\title{
A protocol for the prevention of infection in cochlear implant surgery
}

\author{
By Graeme M. Clark, Brian C. Pyman and Robin E. Pavillard* \\ (Melbourne)
}

THE reduction of infection to an absolute minimum is a very desirable goal in any form of surgery. It is especially important with a cochlear implant operation as infection in the labyrinth can lead to degeneration of the auditory nerve fibres it is hoped to stimulate electrically (Clark et al., 1975). Furthermore, as the implantation of foreign materials increases the risk of infection, as the operation can last 6-7 hours (Altemeier et al., 1976), and as the operators are in very close proximity to the implant site, more stringent measures for the prevention of infection need to be adopted than with other forms of otological surgery. For these reasons a protocol has been developed for preventing infection in our cochlear implant surgery. This is an overall approach to the prevention of infection and involves pre-operative measures, an operating theatre routine, the use of horizontal laminar flow filter units, correct surgical technique and the use of systemic and local antibiotics.

\section{Pre-operative measures}

The incidence of infection is likely to be increased by wound contamination from pathogens shed from the nose, mouth, forehead and hair of the surgical staff. For this reason we have adopted the policy of carrying out nasal swabs, on all the theatre staff involved, ten days before surgery. If a staphylococcus aureus or other significant pathogen is isolated the person is required to spray the nostrils with framycetin three times a day for five days. If a repeat nasal culture is positive, that person is excluded from the theatre until clear. In addition, the surgical staff shampoo their hair with a $17 \cdot 5$ per cent cetrimide solution the night before surgery, and apply a cream to the forehead before scrubbing up to prevent the shedding of skin squames.

The risk of infection is also increased if there are pathogens on the skin in the operative area or close to the operative site. The patient's nose is swabbed ten days before surgery, and if positive, appropriate topical therapy is given. A swab is also taken from the external auditory canal and post-auricular sulcus. A culture from the latter area is important as it is a site of predilection for staphylococcus aureus.

After the swab is taken from the external auditory canal, ear toilet is

* Departments of Otolaryngology and Microbiology, University of Melbourne. 
carried out using the operating microscope. Hairs are clipped, wax removed and the canal cleaned with swabs soaked in 70 per cent alcohol.

The patient is also required to have a hair shampoo with the cetrimide solution the night before operation, and to shower with a 4 per cent solution of chlorhexidine in a foaming base before pre-medication on the morning of operation. A first pre-operative skin preparation with 0.5 per cent chlorhexidine in 70 per cent alcohol is also carried out at this time.

\section{Operating theatre routine}

The operating theatre routine aims to minimize the input of potential pathogens from the general environment. All staff are required to cover footwear with plastic overboots and to wear paper balaclavas which have a tight weave and retain all hair completely. Those involved in the surgery must also remove rings from their fingers. Filter masks (Deserat) are used, and these are strapped to the bridge of the nose. A plastic apron is used during the scrub-up only, to prevent wetting the theatre garb. A $7 \cdot 5$ per cent povidine iodine solution in a foaming base is used for washing the hands. The hands are dried and a separate towel used to dab the water from the forearms.

The patient's hair is clipped and shaved for a distance of $5 \mathrm{~cm}$ beyond the proposed incision. This is carried out in the anaesthetic room under anaesthesia, as it makes the loss of hair more readily accepted by the patient. Once the patient is correctly positioned on the table the skin is prepared with 0.5 per cent chlorhexidine in 70 per cent alcohol. It is applied to the post-auricular area and pinna and allowed to dry. The skin of the external auditory canal is swabbed with 0.5 per cent chlorhexidine in 70 per cent alcohol and any excess aspirated. It is then removed with 70 per cent alcohol. The above routine is repeated twice, and finally a 10 per cent povidine iodine solution is applied and allowed to dry on the skin, and any excess is aspirated from the auditory canal. Head towels are sutured in place, and a body drape correctly positioned. A plastic drape with adhesive backing is applied to the skin after an opening has been cut for the pinna. A longer plastic drape is applied below the operative area to allow irrigation fluid to run downwards and not to wet the drapes at a point where bacterial contamination could come through from the patient into the sterile area.

To prevent wound contamination it is also important to reduce air-borne particles in the theatre air. For this reason the number of personnel and their movements are reduced to a minimum.

\section{Horizontal laminar flow filter unit}

In spite of strict pre-operative measures, and a well disciplined operating theatre routine, there is still a risk that contaminated air-borne particles may reach the operative site. This possibility is further reduced by using a horizontal laminar flow filter unit. Two units made by Gelman 
Clemco have been placed side by side and used for this purpose (Figs. 1 and 2). The units are bolted together and provided with two sets of side arms on which are hung two plastic screens. The side arms are splayed outwards at an angle of $105^{\circ}$ to provide adequate access to the operative area.

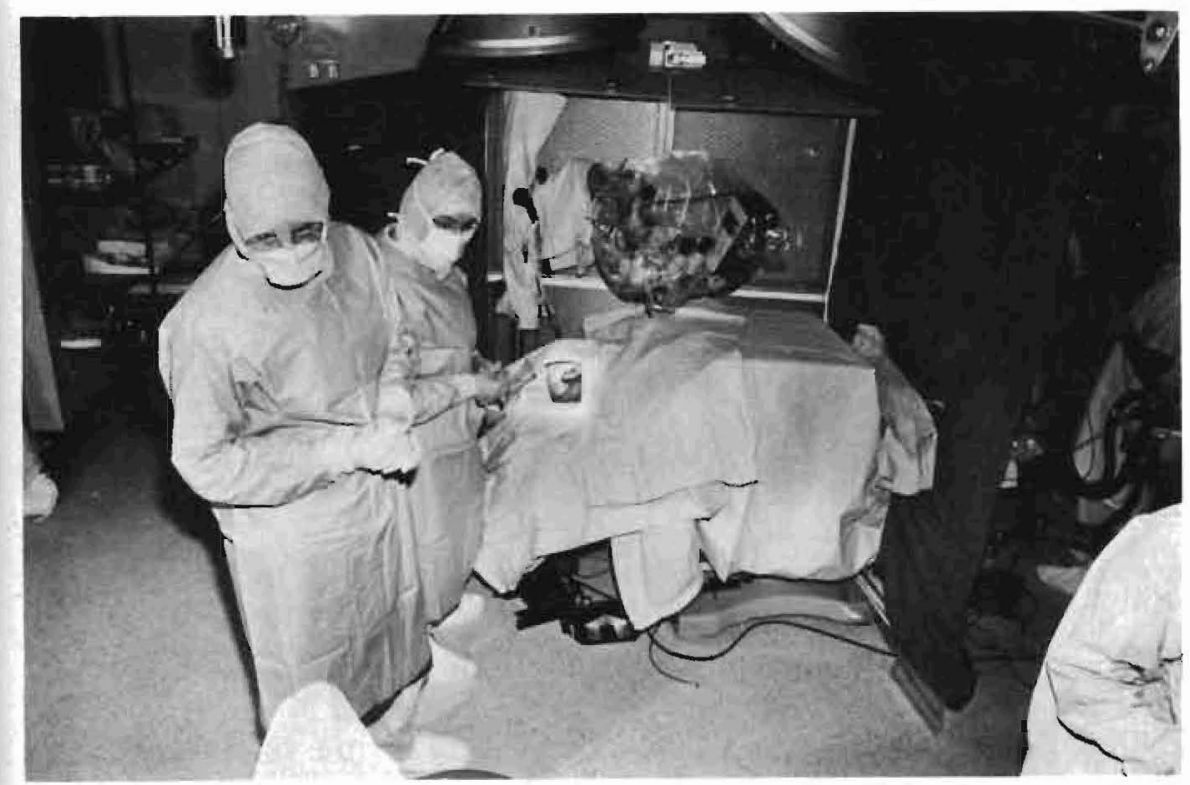

FxG. 1

A photograph of the operative lay-out with horizontal laminar flow filter units for a right multiple-channel cochlear implant operation, following draping of the patient prior to surgery.

A study has been carried out to help determine the efficacy of the horizontal laminar flow filter units. This has been done by asking six volunteers who had no knowledge of the experimental design to sit at a table three feet from the units, with their elbows on the bench, chin resting on their hands and poised directly over a blood agar plate. They were then asked to recite the following sentences ten times and emphasize the labial and glottal consonants:

We spread several species of spiteful bacteria

While speaking, spitting, coughing and sneezing,

It's not the cough that carries us off,

It's the coffin they carry us off in.

This was carried out with and without a mask, and both procedures were made with and without the filter unit on. To avoid an ordering effect, for volunteers 1, 2 and 3 the order of testing was: filter unit on-mask on; filter unit on-mask off; filter unit off-mask on; and filter unit off-mask off; for volunteers 4, 5 and 6 the order of testing was altered to: filter unit 


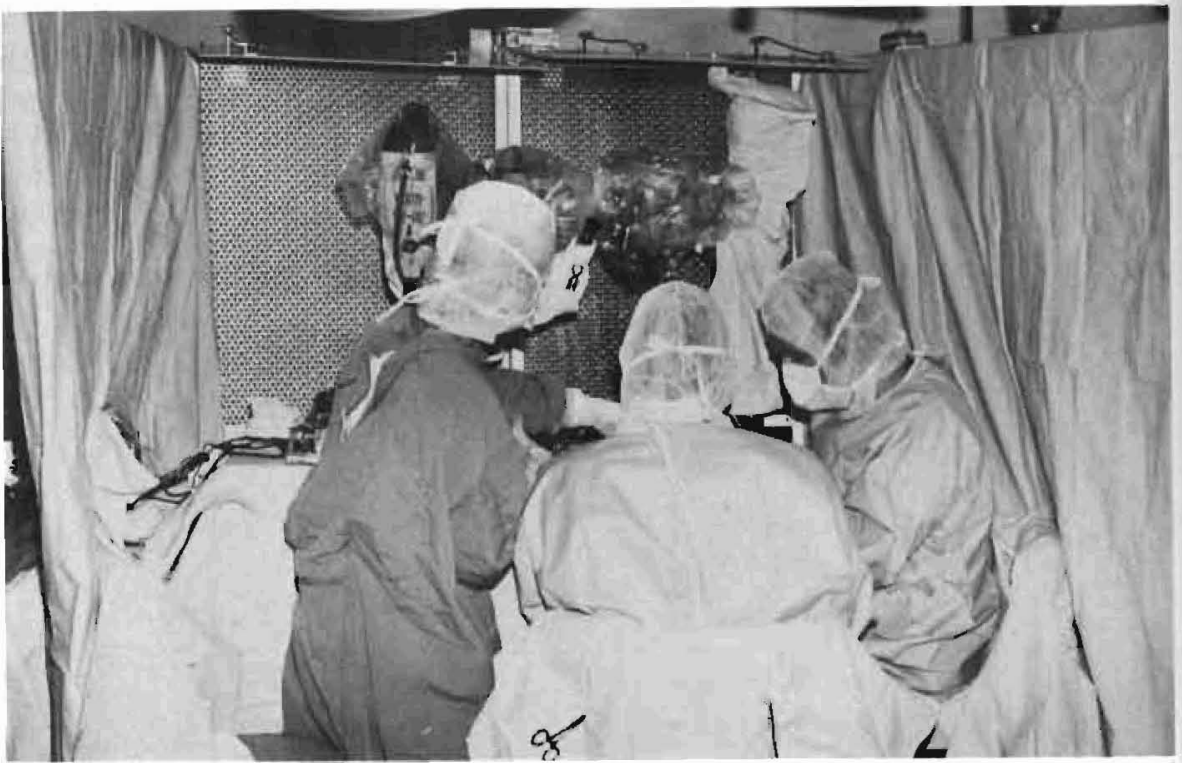

Fig. 2

A photograph of the operative lay-out with horizontal laminar flow filter units for a left multiple-channel cochlear implant operation, during surgery.

off-mask off; filter unit off-mask on; filter unit on-mask off and filter unit on-mask on. The blood agar plates were incubated at $37^{\circ} \mathrm{C}$ for 18 hours, and the number of colonies counted. The results for the six volunteers are shown in Table I. From this it can be seen that the laminar flow unit was capable of reducing colony counts by an average of 60 per cent, even for high risk test situations where no masks were used. The percentage reduction for light contamination situations where a mask was used was 100 per cent.

The use of the filter unit limited the space available and it was necessary to check that the two surgeons, theatre sister and anaesthetist would have

TABLE I

TOTAL NUMBER OF COLONIES COUNTED

\begin{tabular}{|c|c|c|c|c|c|c|}
\hline \multirow{2}{*}{$\begin{array}{l}\text { Subject } \\
\text { number }\end{array}$} & \multicolumn{3}{|c|}{ Mask off } & \multicolumn{3}{|c|}{ Mask on } \\
\hline & Unit off & Unit on & $\%$ reduction & Unit off & Unit on & $\%$ reduction \\
\hline 1 & 400 & 300 & 25 & 2 & 0 & 100 \\
\hline 3 & 364 & 160 & 56 & 3 & 0 & 100 \\
\hline 2 & 360 & 60 & 83 & 4 & 0 & 100 \\
\hline 6 & 132 & 19 & 86 & 3 & 0 & 100 \\
\hline 4 & 102 & 52 & 49 & 2 & 0 & 100 \\
\hline 5 & 88 & 36 & 59 & 0 & 0 & - \\
\hline Mean & & & 60 & & & 100 \\
\hline Range & & & $25-86$ & & & - \\
\hline
\end{tabular}




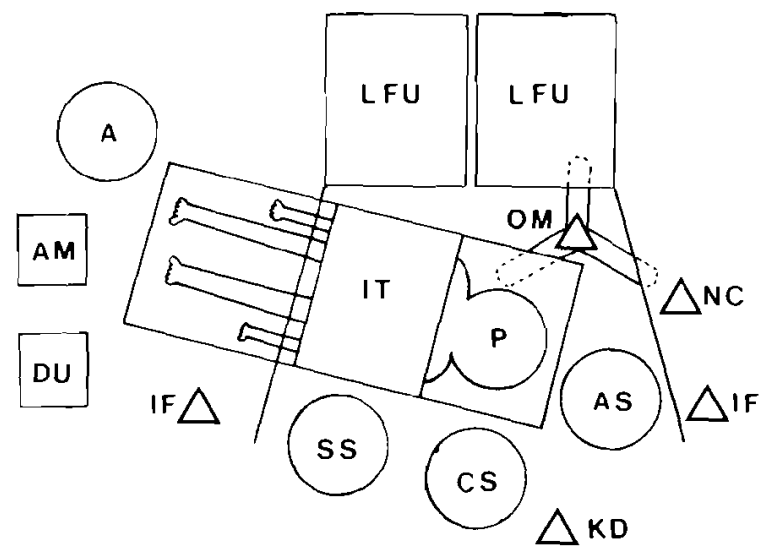

FIG. 3

A diagram of operative lay-out for a multiple-channel cochlear implant operation. A anaesthetist; $\mathrm{AM}=$ = anaesthetic machine; $\mathrm{AS}=$ assistant surgeon; $\mathrm{CS}=$ chief surgeon; $\mathrm{DU}=$ diathermy unit; IF = irrigation fluid; IT = instrument table; $\mathrm{KD}=$ Kavo drill; LFU $\therefore$ laminar flow filter unit $\mathrm{NC}=$ nitrogen cylinder; $\mathrm{OM}=$ operating microscope; $\mathrm{P}=$ patient; $\mathrm{SS}=$ scrub sister.

adequate access to the patient, that there was room to lay out all the instruments required at each stage of the surgery within the laminar flow, and that there was room to position the operating microscope correctly.

It was also necessary to place the personnel 'down stream' from the operative area so that any bacteria shed would not drift into the wound. It was also desirable to have an arrangement whereby turbulence could be kept to a minimum, to reduce the risk of carrying contaminated airborne particles into the wound.

The lay-out that evolved is shown in Fig. 3. The front face of the filter unit is placed at an angle of $15^{\circ}$ to the operating tablc. This leaves room in the top corner for the operating microscope stand, and for the assistant surgeon to sit at the head of the table. It was found that an instrument table $\left(19^{\prime \prime} \times 22^{\prime \prime}\right)$ could be accommodated in the space available. It was necessary to place the anaesthetist at the foot of the table, with access to the patient's hand provided by a flap in the side curtain.

The effectiveness of the laminar flow unit was tested in the operating theatre, employing the lay-out and staff positioning that were to be used for implant surgery. Settle plates were exposed for two hours at the following locations within the laminar flow area; head of table where sucker was in use, centre of table where drill was in use, bottom of table, instrument table, operating microscope, floor at head of table, floor at centre of table, floor at foot of table, and at the following locations elsewhere in the theatre: back of unit $2 \mathrm{ft}$. from floor, between theatre doors $2 \mathrm{ft}$. from floor, in a corner of room behind the unit near autoclave $2 \mathrm{ft}$. from floor, floor behind surgeons' backs. The number of organisms counted after incubating plate for 48 hours are shown in Table II. There 
TABLE II

AIR SAMPLES IN THEATRE SET-UP FOR MULTIPLE CHANNEL COCHLEAR IMPLANT OPERATION

\begin{tabular}{lc}
\hline Site & Number of colonies \\
\hline Laminar flow area & \\
Head of table (sucker in use) & 0 \\
Centre of table (drill in use) & 0 \\
Bottom of table & 1 \\
On microscope & 0 \\
Instrument table & 0 \\
Floor-head of table & 4 \\
Floor-centre of table & 2 \\
Floor-bottom of table & \\
General theatre area & \\
Back of unit-2 $\mathrm{ft}$ off floor & 2 \\
Between door-2 ft off floor & 0 \\
Near autoclave- $2 \mathrm{ft}$ off floor & 3 \\
On floor--back of surgeons & 10 \\
\hline
\end{tabular}

was no contamination at the site of surgery or close to the sucker. The negative count near the sucker is important as a lot of suction is carried out while drilling the mastoid, and this can draw air down over the wound resulting in entrainment of more distant air particles. The high floor count means that air turbulence could lift particles up into the wound.

The performance of the laminar flow filter units in the operation lay-out was assessed by means of a smoke test. This showed that even with the side arms splayed outwards $105^{\circ}$, the air flow was essentially laminar for a distance of six feet from the front face of the unit. There was minimal turbulence generated by the microscope head and stand, and this would be unlikely to cause particles to enter the wound. If the drapes were allowed to hang down below the table, air flowed from low near the floor, up over the table. This important observation emphasizes the need for tucking the drapes under the patient, especially on the side nearest the filter unit. Another important smoke test finding was that, with the unit on, the sucker entrained very little environmental air.

Having established the efficacy of the laminar flow filter unit the following protocol was then adopted so that maximum benefit could be obtained. The filter unit is placed on the side of the theatre where there is least traffic, and switched on half an hour before the patient is brought in. When the patient is placed on the table the microscope is positioned, and the unit brought to a site approximately two-three feet from the table, so that the skin preparation can be done in a clean air environment. The side screens are then attached to the side arms, the microscope and patient draped, and sterile green drapes placed over the side screens. The unit is then wheeled into its final position close to the table, as shown schematically in Fig. 3, and the theatre lay-out is as shown in Figs. 1 and 2. 


\section{Surgical techniques and procedures}

The surgical techniques and procedures used are also designed to minimize the overall risk of infection, and/or the entry of bacteria into the inner ear. First, the initial skin incision is made through the plastic drape. Secondly, when using a drill running on compressed nitrogen, care is taken to make sure the nitrogen is not contaminated with bacteria, particularly anaerobes, as the nitrogen leaks from around the drill into the wound.

To ensure that the nitrogen source is free of micro-organisms, the following procedure has been adopted. The suppliers of nitrogen should collect the air through filters with a particle size no greater than $1 \mu$. The nitrogen cylinders should be of aluminium as they have a smoother internal surface than steel, and are less likely to provide a nidus for bacteria. The cylinders should be kept exclusively for medical purposes as they can get contaminated by back flow, and this is a risk when they are used for other purposes. When filling the cylinders thev are first evacuated, and when filled, heated to $50^{\circ} \mathrm{C}$ and held at this te nperature for thirty minutes to kill vegetative micro-organisms. Any higher temperature is likely to cause unequal expansion of the metal and cylinder leakage. Quality control is carried out on samples of nitrogen taken from the cylinders and cultured in appropriate media.

Thirdly, if the electrode is left passing through the round window, an inevitable small space between it and adjacent bone or surrounding fibrous tissue will exist. This space will always be a potential pathway by which bacteria may reach the cochlea. For this reason we glue a collar of Teflon felt to the electrode with Silastic A medical grade adhesive so that the space alongside the electrode is sealed, and we insert the electrode so that the collar occludes the round window niche. The collar has a mesh-like structure into which fibrous tissue can grow and effectively abolish any possible pathway for bacterial penetration.

To determine which materials with a mesh-like structure allowed a satisfactory ingrowth of fibrous tissue, Silastic sponge, Teflon felt with low porosity and Dacron double velour fabric were implanted into the subcutaneous tissue of rats for 14 days. The material and tissue were sectioned and stained. Photomicrographs of stained sections are shown in Figs. 4, 5 and 6. These show that no fibrous tissue grew into the Silastic sponge, which has a closed cell system, but there was a moderate growth of fibrous tissue into the Teflon felt, and a marked ingrowth of fibrous tissue into the Dacron filamentous with a pronounced foreign body reaction. It was considered that the fibrous tissue ingrowth into Teflon felt was adequate, and this has been used in our patients. The strong reaction to Dacron was considered excessive, as it could lead to fibrous tissue ingrowth into the scala tympani of the basal turn.

Fourthly, only monofilamentous sutures are used deep to the skin as 


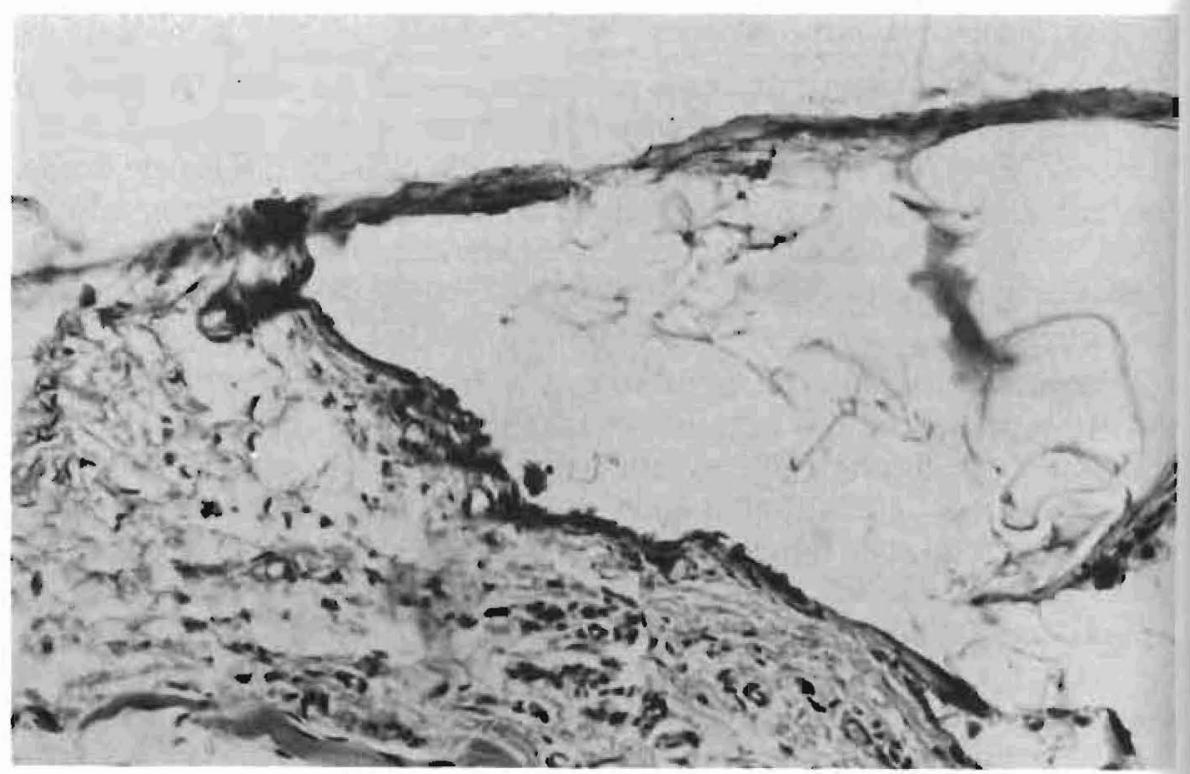

FIG. 4

A photomicrograph of the tissue response to Silastic sponge following implantation in a rat's subcutaneous tissue for 14 days.

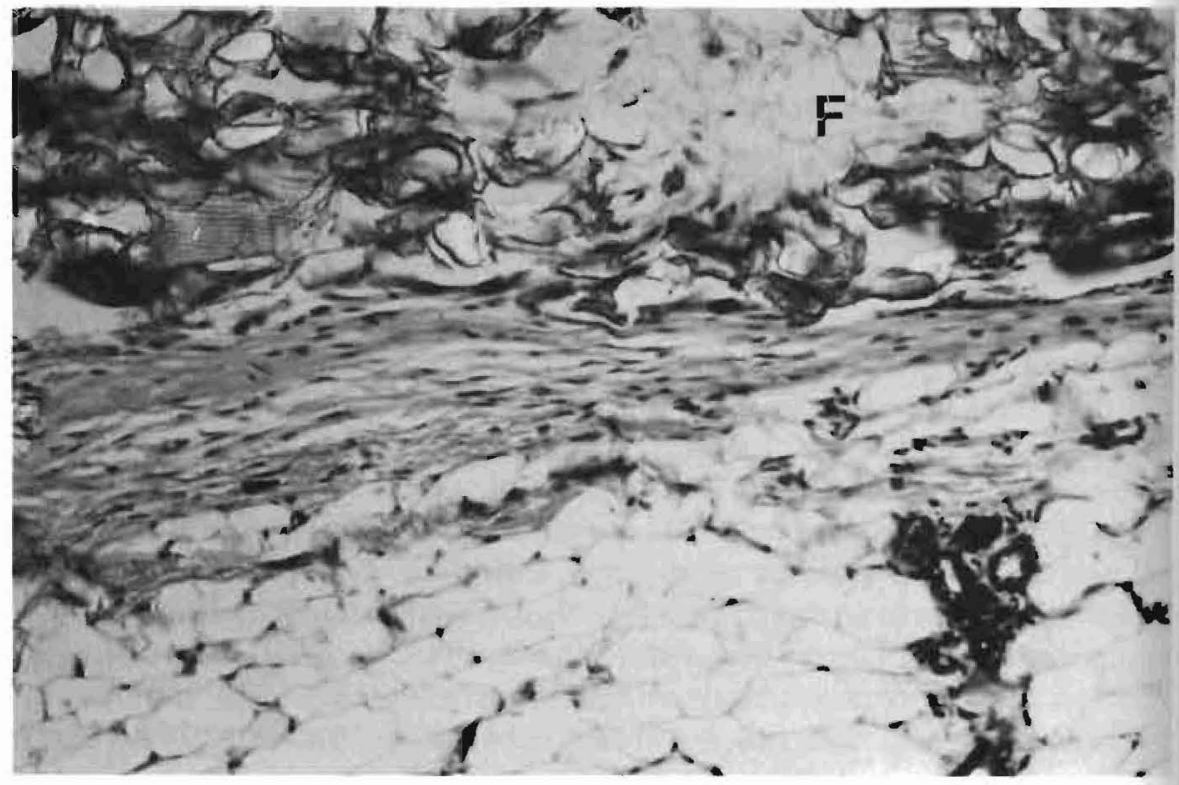

FIG. 5

A photomicrograph of the tissue response to Teflon felt following implantation in a rat's subcutaneous tissue for 14 days. $\mathrm{F}=$ fibrous tissue. 


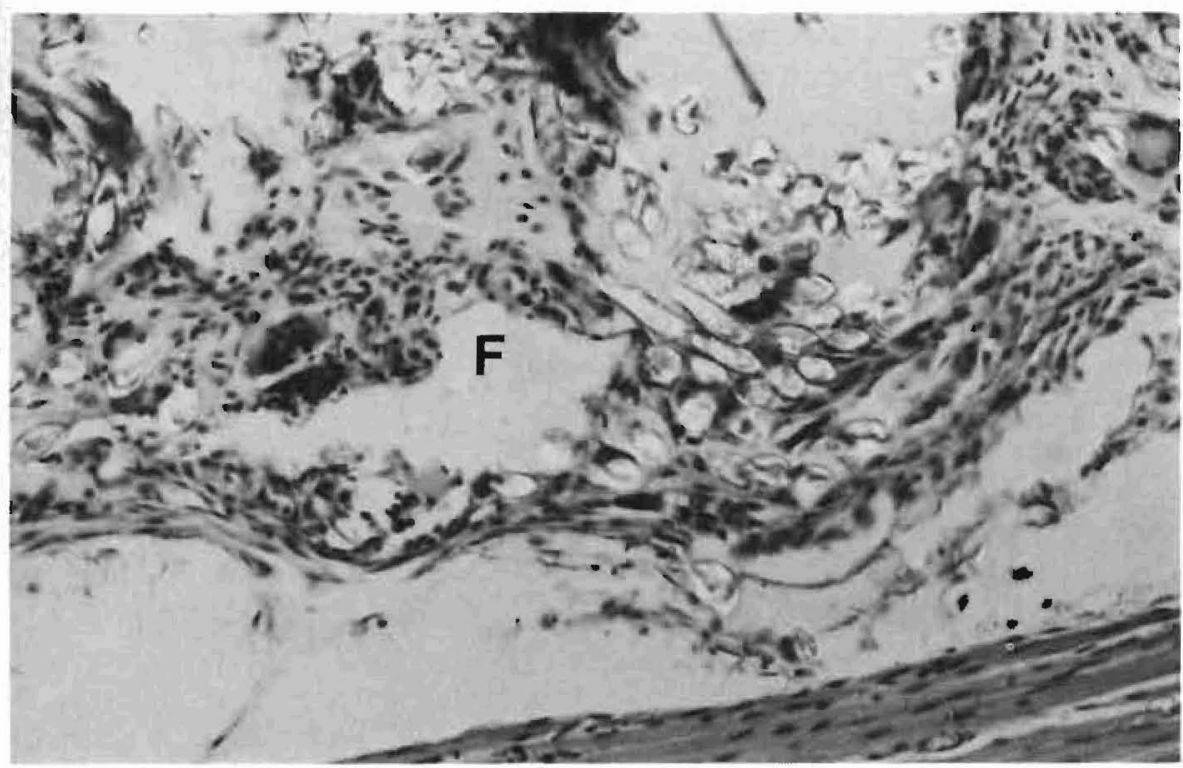

FIG. 6

A photomicrograph of the tissue response to Dacron filamentous following implantation in a rat's subcutaneous tissue for 14 days. $\mathrm{F}=$ fibrous tissue.

these are less likely than woven sutures to be a nidus for infection (James and MacLeod, 1961). Great care is also taken to ensure haemotasis.

\section{Systemic and local antibiotics}

Prophylactic systemic and topical antibiotics are used at the time of surgery, and systemic antibiotics are continued for four days afterwards. The systemic programme is designed to achieve a high blood level at the time of maximum (potential) contamination risk, i.e. when the electrode is being threaded through the round window. For this reason the first dose is given intravenously before the initial incision is made and this is repeated every two hours during surgery, then 4-6 hourly for 96 hours. The sequence consists of $1 \mathrm{~g}$ each of Ampicillin and Cloxacillin, given as bolus injections over five minutes via an intravenous line.

Ampicillin has a broad spectrum of activity and should provide adequate cover against the majority of upper respiratory tract commensals likely to be encountered. Cloxacillin was selected because of its effectiveness against penicillinase-producing strains of nasal and skin Staphylococcus aureus, and at the high dose level used this antibiotic gives additional cover against most upper respiratory tract flora. As soon as the patient is able to take medication orally, $0.5 \mathrm{~g}$ Probenicid is administered four hourly to ensure that serum antibiotic levels do not fall precipitously between intravenous doses of antibiotics.

In order to achieve a high tissue concentration of the antibiotics at the 
operative site a mixture of ampicillin and cloxacillin, in concentrations of ampicillin $(1 \mathrm{mg} / \mathrm{ml})$ and cloxacillin $(0.5 \mathrm{mg} / \mathrm{ml})$, are used up to a total of $25 \mathrm{ml}$. The middle ear is irrigated with a small amount of antibiotic solution before the window is opened and the electrode array is then inserted. This is done to reduce the chance of any contaminating microorganism surviving if they are accidentally carried into the cochlea. This precaution is considered necessary, as preliminary studies have shown that almost no antibiotic is detectable in the perilymph after systemic administration. Ampicillin and cloxacillin are known not to have a significant ototoxic effect and low concentrations in the basal turn are considered desirable at the time of electrode implantation. Before the wound is closed the remaining antibiotic mixture is infiltrated around the implanted receiver-stimulator unit.

In the long term it is recommended that surgical and investigative procedures such as tooth extraction, cytoscopy and sigmoidoscopy, which may be associated with transient bacteraemia, should also be covered with appropriate antibiotics to avoid bacteria being seeded on to the prosthetic implant. Eustachian tube obstruction and/or middle ear infection will require prompt antibiotic treatment.

\section{Acknowledgements}

We would like to acknowledge financial support from the National Health and Medical Research Council of Australia, the Department of Productivity of the Federal Government, the Channel 0 Deafness Appeal, Lions International and the Felton Bequest. We would also like to thank Q. Bailey, R. Black, S. Dickson, Helen Miles, Jane Ng, and R. Webb for their help and Miss Joan Maher for the typing. We would also like to thank the theatre staff of The Royal Victorian Eye and Ear Hospital for their co-operation and the infection control committee for advice.

\section{REFERENCES}

Altemeier, W. A., Burke, J. F., Prutt, B. A., and Sandusky, W. R. (1976) Manual on Control of Infection in Surgical Patients, Chapter 9. Lippincott, Philadelphia.

Clark, G. M., Kranz, H. G., Minas, H., and Nathar, J. M. (1975) Journal of Laryngology and Otology, 89, 495 .

JAMES, R. C., and MACLEOD, C. M. (1961) British Journal of Experimental Pathology, 42, 266.

Reprint requests to:

Professor G. M. Clark,

Department of Otolaryngology,

University of Melbourne,

The Royal Victorian Eye and Ear Hospital,

East Melbourne, 3002,

Australia. 


\section{University Library}

\section{- M M I E R R A A gateway to Melbourne's research publications}

Minerva Access is the Institutional Repository of The University of Melbourne

Author/s:

Clark, Graeme M.;Pyman, Brian C.;Pavillard, Robin E.

Title:

A protocol for the prevention of infection in cochlear implant surgery

Date:

1980

Citation:

Clark, G. M., Pyman, B. C., \& Pavillard, R. E. (1980). A protocol for the prevention of infection in cochlear implant surgery. Journal of Laryngology and Otology, December, 94(12), 1377-1386.

Persistent Link:

http://hdl.handle.net/11343/28723 